This article was downloaded by: [informa internal users]

On: 1 September 2009

Access details: Access Details: [subscription number 755239602]

Publisher Psychology Press

Informa Ltd Registered in England and Wales Registered Number: 1072954 Registered office: Mortimer House, 37-41 Mortimer Street, London W1T 3JH, UK

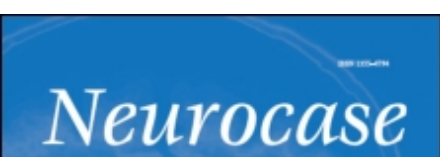

The Neural Basis of Cognition

\title{
Neurocase
}

Publication details, including instructions for authors and subscription information:

http://www.informaworld.com/smpp/title content=t713658146

\section{Detecting consciousness in a total locked-in syndrome: An active event-related paradigm}

Caroline Schnakers a; Fabien Perrin b; Manuel Schabus ${ }^{\text {c; }}$ Roland Hustinx d; Steve Majerus e; Gustave Moonen ; Melanie Boly af; Audrey Vanhaudenhuyse a; Marie-Aurelie Bruno af; Steven Laureys af

${ }^{a}$ Coma Science Group, Cyclotron Research Centre, University of Liège, Liège, Belgium ${ }^{b}$ UMR 5020 ,

Université Claude Bernard Lyon 1 - CNRS, Lyon, France ${ }^{\circ}$ Division of Physiological Psychology, University of Salzburg, Austria and Cyclotron Research Centre, University of Liège, Liège, Belgium ${ }^{d}$ Department of Nuclear Medicine, CHU Sart Tilman, Liège, Belgium ${ }^{\text {}}$ Department of Cognitive Sciences, University of Liège, Liège, Belgium ${ }^{\dagger}$ Department of Neurology, CHU Sart Tilman, Liège, Belgium

First Published on: 25 February 2009

To cite this Article Schnakers, Caroline, Perrin, Fabien, Schabus, Manuel, Hustinx, Roland, Majerus, Steve, Moonen, Gustave, Boly, Melanie, Vanhaudenhuyse, Audrey, Bruno, Marie-Aurelie and Laureys, Steven(2009)'Detecting consciousness in a total locked-in syndrome: An active event-related paradigm',Neurocase, 15:4,271 - 277

To link to this Article: DOI: $10.1080 / 13554790902724904$

URL: http://dx.doi.org/10.1080/13554790902724904

\section{PLEASE SCROLL DOWN FOR ARTICLE}

Full terms and conditions of use: http://www.informaworld.com/terms-and-conditions-of-access.pdf

This article may be used for research, teaching and private study purposes. Any substantial or systematic reproduction, re-distribution, re-selling, loan or sub-licensing, systematic supply or distribution in any form to anyone is expressly forbidden.

The publisher does not give any warranty express or implied or make any representation that the contents will be complete or accurate or up to date. The accuracy of any instructions, formulae and drug doses should be independently verified with primary sources. The publisher shall not be liable for any loss, actions, claims, proceedings, demand or costs or damages whatsoever or howsoever caused arising directly or indirectly in connection with or arising out of the use of this material. 


\title{
Detecting consciousness in a total locked-in syndrome: An active event-related paradigm
}

\author{
Caroline Schnakers, ${ }^{1}$ Fabien Perrin, ${ }^{2}$ Manuel Schabus, ${ }^{3}$ Roland Hustinx, ${ }^{4}$ \\ Steve Majerus, ${ }^{5}$ Gustave Moonen, ${ }^{6}$ Melanie Boly, ${ }^{1,6}$ Audrey Vanhaudenhuyse, ${ }^{1}$ \\ Marie-Aurelie Bruno, ${ }^{1,6}$ and Steven Laureys ${ }^{1,6}$ \\ ${ }^{1}$ Coma Science Group, Cyclotron Research Centre, University of Liège, Liège, Belgium \\ ${ }^{2}$ UMR 5020, Université Claude Bernard Lyon 1 - CNRS, Lyon, France \\ ${ }^{3}$ Division of Physiological Psychology, University of Salzburg, Austria and Cyclotron \\ Research Centre, University of Liège, Liège, Belgium \\ ${ }^{4}$ Department of Nuclear Medicine, CHU Sart Tilman, Liège, Belgium \\ ${ }^{5}$ Department of Cognitive Sciences, University of Liège, Liège, Belgium \\ ${ }^{6}$ Department of Neurology, CHU Sart Tilman, Liège, Belgium
}

\begin{abstract}
Total locked-in syndrome is characterized by tetraplegia, anarthria and paralysis of eye motility. In this study, consciousness was detected in a 21-year-old woman who presented a total locked-in syndrome after a basilar artery thrombosis (49 days post-injury) using an active event-related paradigm. The patient was presented sequences of names containing the patient's own name and other names. The patient was instructed to count her own name or to count another target name. Similar to 4 age- and gender-matched healthy controls, the P3 response recorded for the voluntarily counted own name was larger than while passively listening. This P3 response was observed 14 days before the first behavioral signs of consciousness. This study shows that our active event-related paradigm allowed to identify voluntary brain activity in a patient who would behaviorally be diagnosed as comatose.
\end{abstract}

Keywords: Locked-in syndrome; Evoked potentials; Consciousness; Brain injury; Tetraplegia.

\section{INTRODUCTION}

The locked-in syndrome (LIS) refers to patients who are totally paralyzed but fully conscious and able to use vertical eye movements or blinking in order to communicate (Plum \& Posner, 1966, 1983). More recently, the American Congress of Rehabilitation Medicine (1995) characterized the LIS by the presence of sustained eye opening, aphonia or severe hypophonia, quadriplegia or quadriparesis, preserved cognitive functioning, and a primary and elementary code of communication using vertical eye movements or blinking (American Congress of Rehabilitation Medicine, 1995). According to Bauer, the LIS can nevertheless be subdivided on the basis of motor impairments: classical LIS is characterized by total immobility except for vertical eye movements or

This research was supported by funds from the Belgian Federal Public Service for Public Health, Belgian 'Fonds National de la Recherche Scientifique' (FNRS), 'Centre Hospitalier' of the University of Liège, French Speaking Community of Belgium Concerted Research Action, the J.S. McDonnell Foundation, the European Commission, Mind Science Foundation, TX. SL, SM, and MB are, respectively, Senior Research Associate, Research Associate and Research Fellow at the FNRS. CS is funded by the 'Fonds Léon Fredericq' (University of Liège) and the FNRS.

Address correspondence to Caroline Schnakers, Coma Science Group, Centre de Recherches du Cyclotron, Sart Tilman, B30, University of Liège, 4000 Liège, Belgium. (E-mail: steven.laureys@ulg.ac.be).

(C) 2009 Psychology Press, an imprint of the Taylor \& Francis Group, an Informa business 
blinking; incomplete LIS permits remnants of voluntary motion; and total LIS consists of complete immobility including all eye movements combined with preserved consciousness (Bauer, Gerstenbrand, \& Rumpl, 1979).

Detecting signs of consciousness in these patients is particularly challenging. A study performed in collaboration with the French Association for the LIS (ALIS; http://alis-asso.fr/) showed that physicians realized that the patient was conscious and able to communicate via eye movements in only $62 \%$ of cases (Bruno et al., 2008). Additionally, the time elapsed between the insult and the diagnosis of LIS is about 78 days (Laureys et al., 2005). Difficulties in diagnosis could be explained by the apparent similarity with the vegetative state (i.e., eyes opening and motor immobility without signs of awareness) (The Multi-Society Task Force on PVS, 1994), by the rarity of this syndrome but also by a possible fluctuation of the arousal level in the acute setting or by the difficulty to recognize unambiguous signs of consciousness in severely brain injured patients (Majerus, Gill-Thwaites, Andrews, \& Laureys, 2005). In the case of a total LIS, there are no behavioral signs of consciousness such as oriented eye movements which can be detected. Rates of misdiagnosis are likely to be very high in this extreme form of LIS. Early detection of signs of consciousness in the LIS is crucial as regards to end-of-life decisions but also medical treatment (particularly, considering treatment of pain and anxiety).

As behavioral tools are not sufficient, paramedical tools have therefore to be developed in order to facilitate the detection of signs of consciousness. Electrophysiology constitutes an interesting technique as it requires direct recording of the brain activity without the intervention of behavioral responses. The purpose of the present study is to present an active event-related potentials paradigm which permitted to detect voluntary brain responses in a total LIS patient.

\section{METHODS}

\section{Patient history}

This 21-year-old woman was admitted to the intensive care with headache, diarrhea, vomiting, and dysarthria. She deteriorated becoming apparently comatose. Indeed, she did not open her eyes even with stimulation. Pupillary responses were preserved. Stereotyped response was observed following noxious stimulation. She did not respond to verbal command. No verbalizations were observed. EEG was characterized by diffuse theta activity and preserved somatosensory evoked potentials (N20) were obtained. Magnetic resonance imaging (MRI) showed ischemic lesions of brainstem, cerebellum and left thalamus. There were no abnormalities seen in cortical regions. $\left({ }^{18} \mathrm{~F}\right)$ fluorodeoxyglucose-PET scanning performed 14 days after brain insult revealed an hypometabolism involving brainstem, cerebellum and left thalamus but a preservation of supra-tentorial areas. She required ventilation via a tracheostomy, a percutaneous enterogastrectomy feeding tube, and an indwelling catheter. There was no change during the first 3 weeks, and the patient was transferred to the neurology unit.

As regards to aetiology (i.e., basilar thrombosis) and functional imaging findings (i.e., preservation of supra-tentorial areas), the diagnosis of a 'total' LIS, as described by Bauer et al. (1979) was considered. Cognitive auditory event-related potentials which will be outlined in detail in the next section were therefore performed on the 25th, 39th and 49th day after brain insult to demonstrate the existence of voluntary brain responses in this patient. The patient was free of sedative and other centrally acting drugs for at least $24 \mathrm{~h}$. Fourteen days after the last eventrelated potentials' recordings (63rd day after brain insult), the first sign of consciousness was observed (i.e., inconsistent but reproducible finger movements). At that moment, she was transferred to a rehabilitation centre where she made slow but progressive improvement. Her left arm power recovered from distal to proximal muscles, as has been noted in LIS patients (Richard et al., 1995). Head movements were possible and permitted communication. She smiled in an appropriate context. However, severe emotional lability such as pathologic laughing and crying (i.e., she displayed these emotions involuntarily, often in response to inappropriate stimuli) was noted. She was discharged home 12 months after stroke, fully dependent in all personal activities of daily living. Currently, she still lives with her parents.

Our study was approved by the Ethics Committee of the University of Liège and written informed consent was obtained from the patient's legal surrogate. 


\section{Event-related paradigm}

Nine sequences of 120 auditory stimuli were developed. Each sequence included 8 first names (the subject's own name and 7 other unfamiliar names) repeated 15 times and presented in a randomized order. The unfamiliar names were selected from previous studies (Perrin, Garcia-Larrea, Mauguiere, \& Bastuji, 1999; Perrin et al., 2006) and are all of common use in the French language. The inter-stimulus interval time was of $1500 \mathrm{~ms}$. Each patient's family was asked whether some of the unfamiliar names had an emotional importance for the patient (e.g., close relatives name). The emotionally significant names were excluded from the analysis. All stimuli had been recorded by the same female voice with a neutral intonation, digitized and were then replayed binaurally during the experiment (at maximum $90 \mathrm{~dB}$ sound pressure level).

The event-related paradigm included one passive and two active conditions ( 3 sequences per condition). The passive listening condition was first presented to the subject and was followed by two active conditions presented in randomized order. In the active conditions, the patient was asked to either count one specified target unfamiliar name (target unfamiliar name condition), or to count her/his own name (own name condition).

\section{Event-related potentials' acquisition}

Stimuli were presented via earphones and data were acquired at the bedside. Event-related potentials' recordings were performed with the eyes closed and minimal ambient noise. Eventrelated potentials were recorded from $\mathrm{Fz}, \mathrm{Cz}$ and $\mathrm{Pz}$ (Klem, Luders, Jasper, \& Elger, 1999) and referenced to the nose. Electro-oculogram (EOG) was acquired using 2 electrodes placed diagonally above and below the right eye. A ground electrode was placed near $\mathrm{Fz}$ and impedances were kept below $5 \mathrm{k} \Omega$. Data were collected at a sampling rate of $500 \mathrm{~Hz}$ using a NuAmp EEG amplifier (NeuroSoft, Sterling, VA, USA) with analog bandpass filtering of $0.1-200 \mathrm{~Hz}$. Standardized stimulation (i.e., deep pressure and auditory stimuli) was performed prior to each sequence to improve arousal (Giacino, Kalmar, \& Whyte, 2004). Additionally, event-related potentials was performed when bispectral monitoring (Aspect Medical Systems, Newton, USA) showed bispectral index values above 90 (Sleigh, Andrzejowski, Steyn-Ross, \& Steyn-Ross, 1999). A 5min break separated each condition of the eventrelated paradigm.

\section{Event-related potentials' analysis}

Using Neuroscan software (NeuroSoft, Sterling, VA, USA), single epochs (-200 to $1300 \mathrm{~ms}$ ) with an amplitude $\geq \pm 75 \mu \mathrm{v}$ on EOG electrodes were discarded from further analysis. Event-related potentials were averaged as a function of target (i.e., the subject's own name or the target unfamiliar name) and non-target (i.e., average of the 6 not-to-be-counted unfamiliar names) events in each condition. In order to ensure equivalent signal-to-noise ratios, we compared eventrelated potentials to targets and non-targets obtained with a same number of trials (i.e., nontargets preceding the targets were selected). For illustrative propose, the averaged data were digitally filtered from 1 to $40 \mathrm{~Hz}(6 \mathrm{db})$. Four agematched healthy control subjects (3 women; 25 years old) were also recorded. Grand-averaged event-related potentials were constructed for control subjects.

\section{Statistical analysis}

Amplitudes and latencies of the N1, P2, N2 and P3 components were calculated for individual averages. For each component, we choose the maximum amplitude and its associated latency (in a temporal window predefined on grandaveraged event-related potentials). Amplitude differences (1) between targets (i.e., the subject's own name and the target unfamiliar name) and non-targets (i.e., not-to-be-counted unfamiliar names) in each of the 3 conditions and (2) between targets in passive and targets in active conditions were tested at an individual level at $\mathrm{Fz}, \mathrm{Cz}$ and $\mathrm{Pz}$ using $T$ scores. This analysis takes into account the variance of the EEG recordings composing the averaged event-related potentials (Perrin et al., 2006). $T$ scores were computed for control subjects and patient in a temporal window of $50 \mathrm{~ms}$ around the peak latency of each component. Results were considered significant when $p$ values were below .05 within the temporal window of $50 \mathrm{~ms}$. Additionally, in order to determine whether the patient's amplitudes and latencies were significantly different $(p<.05)$ 
from control performance, modified $t$-tests were performed (Crawford \& Garthwaite, 2002).

\section{Behavioral assessment}

Before each event-related potentials' assessment, the consciousness level was determined by means of the Coma Recovery Scale-Revised (Giacino et al., 2004). This scale consists of 23 hierarchically arranged items that comprise six subscales addressing arousal, auditory, visual, motor, oromotor/verbal and communication functions. The lowest item on each subscale represents reflexive activity while the highest item represents cognitively-mediated behaviors.

\section{RESULTS}

Considering the four controls' grand average, a larger P3 response was observed for the subject's own name vs. the unfamiliar names in the passive condition (at Fz, Cz and Pz). Moreover, a significantly higher P3 was obtained when the targets (i.e., the subject's own name and the target unfamiliar name) had to be counted (active conditions) rather than only listened to (passive condition) (at
$\mathrm{Fz}, \mathrm{Cz}$ and $\mathrm{Pz}$ sites). A larger $\mathrm{P} 3$ was also observed, for the counted targets as compared to passive listening to unfamiliar names (at $\mathrm{Fz}, \mathrm{Cz}$ and $\mathrm{Pz}$ sites) (Table 1 and Figure 1). Additionally, each control subject had a larger P3 response for the own name in the passive condition as well as a larger P3 response for the counted targets in the active condition. The results were hence identical when considering each control subject individually.

For the patient, event-related potentials' recordings were performed on the 25th, 39th and 49th day after brain insult. Significant task related P3 changes were observed in the last recording session (i.e., 49th day post-insult). During this session, the patient had firstly to count the target unfamiliar name (target unfamiliar name condition) and then to count the own name (own name condition). The results presented here are based only on this last event-related potentials' assessment session.

For this assessment, a larger P3 response was observed for the subject's own name vs. the unfamiliar names in the passive condition (at $\mathrm{Cz}$ ). Moreover, a significantly higher P3 was obtained when the subject's own name had to be counted (in the active condition) rather than only listened to (in the passive condition) (at $\mathrm{Cz}$ and $\mathrm{Pz}$ ). A larger $\mathrm{P} 3$ was

TABLE 1

(a) Upper panel: event-related potentials' amplitudes (in $\mu \mathrm{v}$ ) at Pz for P3 component in response to subject's own name (SON) in both passive (listened SON) and active (counted SON) conditions for our LIS patient, for the control group (average) and for each control subject $(n=4)$ The mark $\left(^{*}\right)$ indicates differences $(p<.05)$ in P3 amplitudes obtained for the counted vs. the listened SON and the counted SON vs. non counted unfamiliar names (UN). (b) Lower panel: event-related potentials' amplitudes (in $\mu \mathrm{v}$ ) at Pz for P3 component in response to the target unfamiliar name (TUN) in both passive (listened TUN) and active (counted TUN) conditions for our LIS patient, for the control group (average) and for each control subject $(n=4)$. The mark $\left(^{*}\right)$ indicates differences $(p<.05)$ in P3 amplitudes obtained for the counted vs. the listened TUN and the counted TUN vs. non counted unfamiliar names (UN)

\begin{tabular}{lllll}
\hline & Listened SON & Counted SON & $\begin{array}{c}\text { Counted } v \text {. } \\
\text { Listened SON }\end{array}$ & $\begin{array}{c}\text { Counted } \\
\text { SON vs. UN }\end{array}$ \\
\hline LIS & 11.7 & 12.6 & $*$ & $*$ \\
Controls & $5.5 \pm 1.9$ & $14.6 \pm 5.1$ & $*$ & $*$ \\
Control 1 & 3.7 & 18 & $*$ & $*$ \\
Control 2 & 7.2 & 16.3 & $*$ & $*$ \\
Control 3 & 4 & 7.1 & $*$ & $*$ \\
Control 4 & 7.1 & 17.1 & $*$ & Counted \\
\hline & & & Counted $v$. & TUN vs. UN \\
& Listened TUN & Counted TUN & Listened TUN & - \\
LIS & 5.1 & 5.7 & - & $*$ \\
Controls & $3.1 \pm 1.8$ & $10.9 \pm 2.1$ & $*$ & $*$ \\
Control 1 & 2 & 12.4 & $*$ & $*$ \\
Control 2 & 5.7 & 12.7 & $*$ & $*$ \\
Control 3 & 2.8 & 8.2 & $*$ & $*$ \\
Control 4 & 1.8 & 10.2 & $*$ & $*$ \\
\hline
\end{tabular}


LIS patient
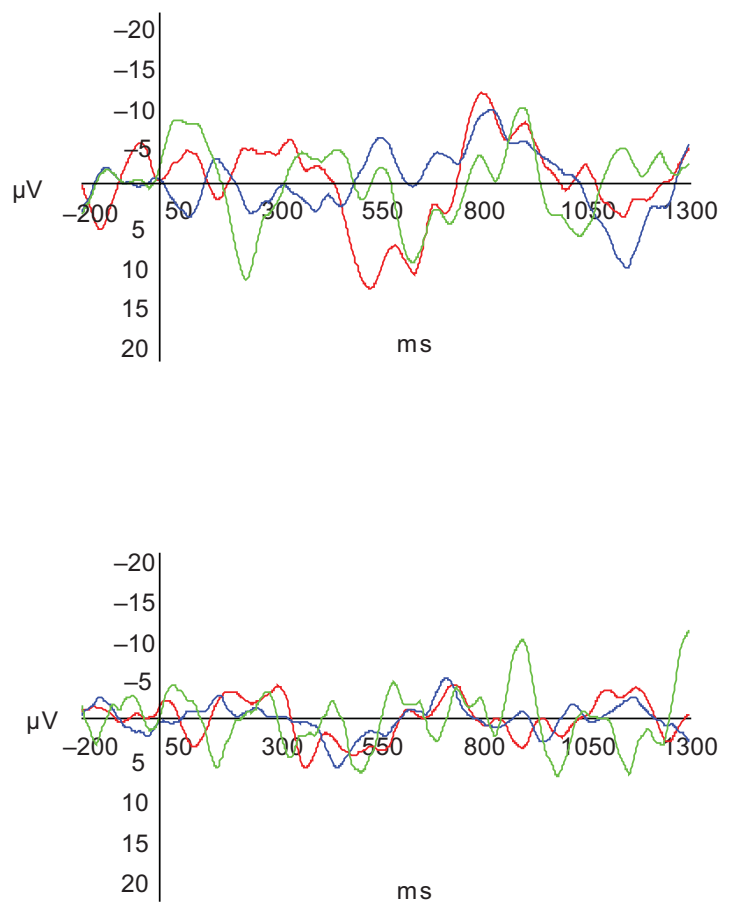

Healthy volunteers
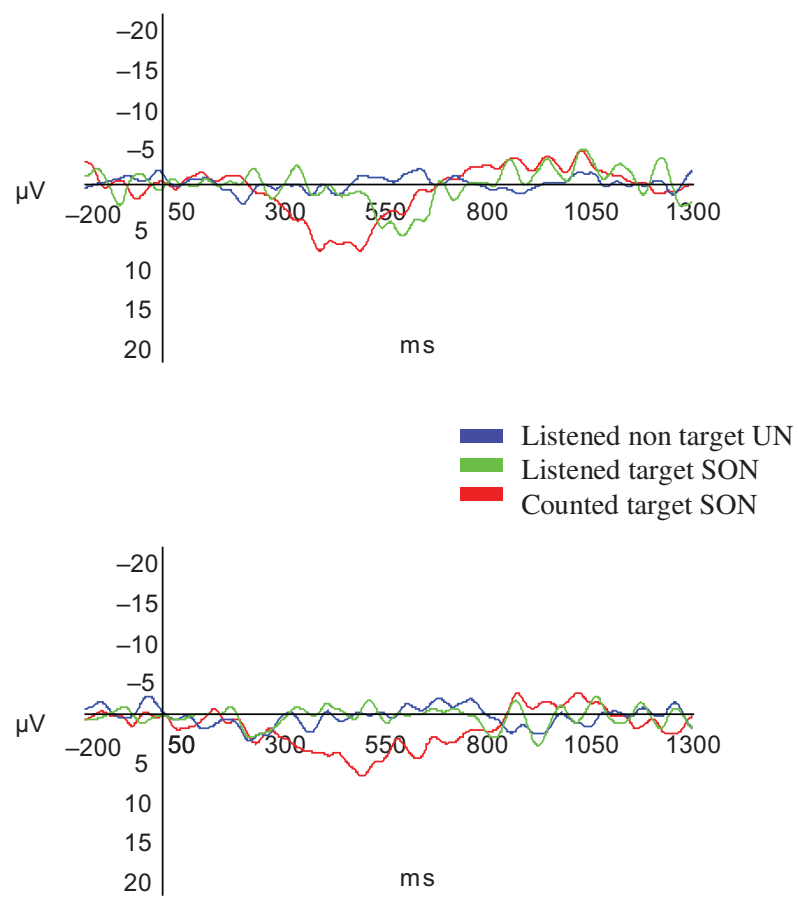

Listened non target UN Listened target TUN Counted target TUN

Figure 1. Grand-averaged event-related potentials in our LIS patient and in healthy volunteers $(n=4)$ at Pz. Upper panels depict the response to the subject's own name (SON) in the passive condition (listened target SON; in green) and in the active condition (counted target SON; in red) vs. unfamiliar names (listened non-targets UN; in blue). Lower panels depict the response to the target unfamiliar name (TUN) in the passive condition (listened target TUN; in green) and in the active condition (counted target TUN; in red) vs. unfamiliar names (listened non-targets UN; in blue). To view this figure in colour, please visit the online version of this issue.

also observed in the active condition for the counted subject's own name as compared to non-counted targets (i.e., unfamiliar names) (at $\mathrm{Fz}$ and $\mathrm{Pz}$ ). However, no larger P3 response was observed for the counted target unfamiliar name (in the active condition) as compared to the listened target unfamiliar name (in the passive condition) or as compared to non-counted targets (i.e., unfamiliar names in the active condition) (Table 1 and Figure 1).

The amplitude of P3 responses was not significantly different between the patient and controls for the subject's own name in passive and active conditions. However, the latency of P3 responses significantly differed between controls and the patient for the counted subject's own name in the active condition $(\mathrm{Fz}, t=6.1, p<.01 ; \mathrm{Cz}, t=4.9, p<.01 ; \mathrm{Pz}, t=$ $4.5, p=.01)$; higher latencies being observed in our patient as compared to controls.
Finally, at a behavioral level, the patient showed no eye opening, no response-to-command related eye movements (following manual eye opening), no visual fixation or tracking, no visual or auditory startle, but bilateral Babinski signs with hyperreflexive quadriplegia, abnormal posturing to pain and oral reflexive movement. Additionally, we observed preserved pupillary responses to light. Vertical and horizontal oculocephalic reflexes were nevertheless absent.

\section{DISCUSSION}

In our patient and in all controls, we found a larger $\mathrm{P} 3$ response following the presentation of the own name in the passive condition. This result could suggest that our patient was able to consciously 
detect her own first name. However, a previous study of Perrin et al., 2006) showed a larger amplitude in response to the patients' own name as compared to unfamiliar names in all controls but also in 3 out 5 patients diagnosed as being in a vegetative state. Furthermore, it is known that speech processing can be observed in unconscious state such as anesthesia (Davis et al., 2007) or sleep (Perrin et al., 1999). Therefore, responses observed during passive listening conditions probably reflect automatic speech processing and are not sufficient to suggest voluntary and therefore conscious brain activity.

Using our active event-related paradigm, we observed that our patient had a larger P3 response for the counted subject's own name as compared to the not-to-be counted names and as compared to passive listening of the subject's own name. In addition, the P3 amplitude observed in these conditions was similar to that observed in controls. This suggests that, like controls, the patient was able to understand and to respond to verbal instructions (i.e., she could voluntary focalize her attention on the target stimulus). Additionally, the bispectral index was superior to 90 during the event-related potentials' recording. This would exclude a comatose state. Indeed, a previous study has shown that unconscious severely brain injured patients (i.e., in a coma or in a vegetative state) had a mean bispectral index value inferior to 50 , whereas conscious severely brain injured patients (i.e., in a minimally conscious state or emerging from this state) had a mean bispectral index value superior to 50 (Schnakers, Majerus, \& Laureys, 2005). Our results can also be related to those observed in a case report using an active eventrelated fMRI paradigm (i.e., mental imagery) which showed brain activation patterns similar to controls in one patient diagnosed as being in a vegetative state, suggesting that this patient was actually able to voluntarily follow task instructions, and hence was conscious to some extent (Owen et al., 2006). Our study stresses the interest of active event-related paradigms for detecting signs of consciousness and underlines the possibility to use these paradigms at the patient's bedside by means of cognitive evoked potentials. Finally, it is interesting to note that this voluntary brain activity was detected 14 days before the first behavioral signs of consciousness (i.e., a reproducible response to verbal order - 'move your finger', appearing with the recovery of some motor activity).

Our results showed a larger P3 response for the counted subject's own name during the third recording (i.e., 49th day after the onset). The absence of response during the first and second assessments (i.e., 25th and 39th day after the onset, respectively) can be related to the Onofrj and colleagues' study. In this study, the authors observed the reappearance of $\mathrm{P} 3$ responses in a locked-in patient only 55 days post onset (Onofrj, Melchionda, Thomas, \& Fulgente, 1996). This result could be partly explained by initially impaired consciousness levels. Indeed, the time course would be consistent with the patient being comatose early on and eventually entering a minimally conscious state (i.e., inconsistent but reproducible signs of awareness) (Giacino et al., 2002) on the last recording. Recently, we observed that 9 out of 14 minimally conscious patients presented a larger P3 to the to-be-counted target name suggesting voluntary compliance to task instructions (Schnakers et al., 2008). Similarly to our patient, we observed a larger latency for the to-be-counted target name in these patients as compared to controls, reflecting a suboptimal recruitment of cognitive processes necessary to perform the task. Additionally, responses were observed in only one of the two active conditions. This was interpreted to be related to vigilance fluctuations which are characteristic of patients in a minimally conscious state (Giacino et al., 2002). These results are similar to what we observed in our patient as the P3 response observed was obtained in only one of the two active conditions (i.e., the own name condition). However, the existence of fluctuations in vigilance cannot be ruled out. This result could also be explained by the fact that actively counting the own name is easier to perform than counting an unfamiliar name. Indeed, it is well documented that the own name is a powerful attention grabbing stimulus that elicits an automatic increase of vigilance (e.g., 'cocktail party phenomenon') (Laureys, Perrin, \& Bredart, 2007). Drawing attention to an already salient stimulus such as the subjects own name might thus be more easily achieved than scanning all other names against the to-be-counted target name. Moreover, our patient presented a lesion in the thalamus which is known to be part of attentional and short-term memory networks necessary in maintaining and updating information during a counting task (Constantinidis \& Procyk, 2004).

The fundamental finding here is that our patient was able to respond as a function of task requirements in at least one of the conditions, suggesting that they are able to voluntarily follow relatively complex task demands, even if only inconsistently 
so. In conclusion, this active auditory event-related paradigm (requiring explicit comprehension of auditory-verbal instructions) provides an interesting tool for detecting voluntary brain activity in patients that behaviorally would be diagnosed as comatose. This paradigm nevertheless needs to be validated in larger groups of LIS patients.

Original manuscript received 10 September 2008
Revised manuscript accepted 10 December 2008
First published online 25 February 2009

\section{REFERENCES}

American Congress of Rehabilitation Medicine (1995). Recommendations for use of uniform nomenclature pertinent to patients with severe alterations of consciousness. Archives of Physical Medicine and Rehabilitation, 76, 205-209.

Bauer, G., Gerstenbrand, F., \& Rumpl, E. (1979). Varieties of the locked-in syndrome. Journal of Neurology, 221(2), 77-91.

Bruno, M. A., Pellas, F., Schnakers, C., Van Eeckhout, P., Bernheim, J., Pantke, K. H., et al. (2008). [Blink and you live: The locked-in syndrome]. Revue Neurologique (Paris), 164(4), 322-335.

Constantinidis, C., \& Procyk, E. (2004). The primate working memory networks. Cognitive Affective \& Behavorial Neuroscience, 4(4), 444 465.

Crawford, J. R., \& Garthwaite, P. H. (2002). Investigation of the single case in neuropsychology: Confidence limits on the abnormality of test scores and test score differences. Neuropsychologia, 40(8), 1196-1208.

Davis, M. H., Coleman, M. R., Absalom, A. R., Rodd, J. M., Johnsrude, I. S., Matta, B. F., et al. (2007). Dissociating speech perception and comprehension at reduced levels of awareness. Proceedings of the National Academy of Sciences of the United States of America, 104(41), 16032-16037.

Giacino, J., Ashwal, S., Childs, N., Cranford, R., Jennett, B., Katz, D. I., et al. (2002). The minimally conscious state: Definition and diagnostic criteria. Neurology, 58(3), 349-353.

Giacino, J., Kalmar, K., \& Whyte, J. (2004). The JFK Coma Recovery Scale-Revised: Measurement characteristics and diagnostic utility. Archives of Physical Medicine and Rehabilitation, 85(12), 2020-2029.

Klem, G. H., Luders, H. O., Jasper, H. H., \& Elger, C. (1999). The ten-twenty electrode system of the International Federation. The International Federation of Clinical Neurophysiology. Electroencephalography and Clinical Neurophysiology (Suppl.), 52, 3-6.

Laureys, S., Pellas, F., Van Eeckhout, P., Ghorbel, S., Schnakers, C., Perrin, F., et al. (2005). The locked-in syndrome: What is it like to be conscious but paralyzed and voiceless? Progress in Brain Research, 150, 495-511.

Laureys, S., Perrin, F., \& Bredart, S. (2007). Selfconsciousness in non-communicative patients. Consciousness and Cognition, 16(3), 722-741.

Majerus, S., Gill-Thwaites, H., Andrews, K., \& Laureys, S. (2005). Behavioral evaluation of consciousness in severe brain damage. Progress in Brain Research, 150, 397-413.

Onofrj, M., Melchionda, D., Thomas, A., \& Fulgente, T. (1996). Reappearance of event-related P3 potential in locked-in syndrome. Cognitive Brain Research, 4(2), 95-97.

Owen, A., Coleman, M., Boly, M., Davis, M. H., Laureys, S., \& Pickard, J. (2006). Detecting awareness in the vegetative state. Science, 313(5792), 1402.

Perrin, F., Garcia-Larrea, L., Mauguiere, F., \& Bastuji, H. (1999). A differential brain response to the subject's own name persists during sleep. Clinical Neurophysiology, 110(12), 2153-2164.

Perrin, F., Schnakers, C., Degueldre, C., Schabus, M., Goldman, S., Brédart, S., et al. (2006). Brain response to one's own name in vegetative state, minimally conscious state and locked-in syndrome. Archives of Neurology, 63(4), 562-569.

Plum, F., \& Posner, J. B. (1966). The diagnosis of stupor and coma (1st ed.). Philadelphia, PA: Davis, F.A.

Plum, F., \& Posner, J. B. (1983). The diagnosis of stupor and coma (3rd ed.). Philadelphia, PA: Davis, F.A.

Richard, I., Pereon, Y., Guiheneu, P., Nogues, B., Perrouin-Verbe, B., \& Mathe, J. F. (1995). Persistence of distal motor control in the locked in syndrome. Review of 11 patients. Paraplegia, 33(11), 640-646.

Schnakers, C., Majerus, S., \& Laureys, S. (2005). A comparison of behavioural assessement tools and electrophysiological measures of recovery from coma. Neuropsychological Rehabilitation, 15, 381-388.

Schnakers, C., Perrin, F., Schabus, M., Majerus, S., Ledoux, D., Damas, P., et al. (2008). Voluntary brain processing in disorders of consciousness. Neurology. $71(20), 1614-1620$.

Sleigh, J. W., Andrzejowski, J., Steyn-Ross, A., \& Steyn-Ross, M. (1999). The bispectral index: A measure of depth of sleep? Anesthesia \& Analgesia, 88(3), 659-661.

The Multi-Society Task Force on PVS (1994). Medical aspects of the persistent vegetative state (1). New England Journal of Medicine, 330(21), 1499-1508. 